\title{
Cannabis use and other predictors of the onset of daily cigarette use in young men: what matters most? Results from a longitudinal study
}

\author{
Julia Becker ${ }^{1}$, Michael P. Schaub ${ }^{1 *}$, Gerhard Gmel ${ }^{2,3,4,5}$ and Severin Haug ${ }^{1}$
}

\begin{abstract}
Background: According to the gateway hypothesis, tobacco use is a gateway of cannabis use. However, there is increasing evidence that cannabis use also predicts the progression of tobacco use (reverse gateway hypothesis). Unfortunately, the importance of cannabis use compared to other predictors of tobacco use is less clear. The aim of this study was to examine which variables, in addition to cannabis use, best predict the onset of daily cigarette smoking in young men.

Methods: A total of 5,590 young Swiss men (mean age $=19.4$ years, $S D=1.2$ ) provided data on their substance use, socio-demographic background, religion, health, social context, and personality at baseline and after 18 months. We modelled the predictors of progression to daily cigarette smoking using logistic regression analyses $(n=4,230)$.

Results: In the multivariate overall model, use of cannabis remained among the strongest predictors for the onset of daily cigarette use. Daily cigarette use was also predicted by a lifetime use of at least 50 cigarettes, occasional cigarette use, educational level, religious affiliation, parental situation, peers with psychiatric problems, and sociability.

Conclusions: Our results highlight the relevance of cannabis use compared to other potential predictors of the progression of tobacco use and thereby support the reverse gateway hypothesis.
\end{abstract}

\section{Background}

Many variables could be important for the progression of tobacco use. The identification of the relevant ones that best predict the progression of tobacco use is highly important because tobacco use is, by far, more widespread than cannabis and other illicit drug use and accounts for a significantly greater global burden of disease [1]. Identifying which young adults show a higher risk of transition to more involved stages of tobacco use would be helpful for indicative prevention efforts in this age group.

One of the discussed predictors of tobacco use is cannabis use. Tobacco use can act as a gateway to cannabis use [2], but the reverse has also been observed, i.e., cannabis use acting as a gateway to the initiation of tobacco

\footnotetext{
* Correspondence: michael.schaub@isgf.uzh.ch

'Swiss Research Institute for Public Health and Addiction ISGF, University of Zurich, Konradstrasse 32, CH-8031 Zurich, Switzerland

Full list of author information is available at the end of the article
}

use [3, 4]. Furthermore, the probability of progressing from occasional to regular tobacco smoking and nicotine dependence is higher in smokers who also use cannabis [4-6]. However, the underlying mechanisms connecting tobacco and cannabis use are less clear but are assumed to go beyond the mechanisms underlying the co-use of substances such as tobacco and alcohol in general [7]. Moreover, the relative importance of the mechanisms that contribute to the co-use of tobacco and cannabis may vary across development [8] and stages of use [9].

The way of substance administration is probably among the most important connecting mechanisms of tobacco and cannabis use. In the qualitative study by Amos and colleagues [10], many participants reported that smoking joints, i.e., co-administration of cannabis and tobacco, served as a gateway to smoking cigarettes. A study by Agrawal and Lynskey [11] underlined the importance of the way of administration in linking cannabis and tobacco use. In this study, smoking tobacco was 
significantly associated with cannabis use and dependence whereas the use of smokeless tobacco was not. Because of the shared route of administration, tobacco and cannabis smoking may serve as behavioural cues for one another and therefore reinforce one another [7]. Moreover, the cross-drug reinforcement of tobacco and cannabis use also occurs on a pharmacological level. Tobacco and cannabis affect the same neural pathways, with some systems being mutually enhanced by the two substances and others having contrasting effects [12]; additionally, nicotine may prolong and enhance the subjective effects of cannabis $[3,13]$. The co-administration of cannabis and tobacco is the most widespread way of cannabis administration in many countries, such as Australia [14] and Switzerland, where $97.3 \%$ of young cannabis using men reported mulling, i.e., smoking cannabis as joints mixed with tobacco [15]. In the United States, cannabis is often wrapped in a tobacco leaf and smoked as "blunts" [16] and the majority of cannabis users additionally smoke cigarettes [17]. It is therefore crucial to evaluate the importance of cannabis use in predicting the initiation of cigarette smoking or progression from occasional to regular cigarette smoking.

Apart from the way of administration, the common liability model can also explain the strong association between tobacco and cannabis use. This model assumes that a common liability to using both licit and illicit drugs puts an individual at risk for using both legal and illegal substances, such as tobacco and cannabis. This liability may include a genetic and individual vulnerability, such as proneness to deviant personality and familial liability to addiction [18]. Peer influences in adolescence appear to be one factor that influences individual vulnerability. By analysing the origins of the correlation between tobacco, alcohol, and cannabis use among adolescents, an Australian study found an individual's vulnerability to substance use to be an explaining factor [19]. Vulnerability, in turn, was predicted by the extent to which the individual was affiliated with delinquent and substance using peers.

Other potential predictors that could influence tobacco and/or cannabis use are religiosity and context variables such as socio-economic status or changes in social environments. Religious and pro-social activities are negatively associated with late-onset cannabis use [11] whereas substantial gains or losses in religiosity from childhood to adulthood are positively associated with substance use and misuse in the general U.S. population [20]. A recent longitudinal study suggested that individuals who experienced a declining socio-economic position from childhood to adulthood may be twice as likely to use tobacco and cannabis compared to individuals with a stable trajectory [21].

The aim of this study was to explore how the onset of daily cigarette smoking can be best predicted from a comprehensive set of variables, including cannabis use.

\section{Methods}

\section{Study design and procedure}

The present data are part of the Cohort Study on Substance Use Risk Factors (C-SURF), a longitudinal study designed to assess substance use patterns and their related consequences in young Swiss men. Enrolment in the study occurred between 2010 and 2011 in three Swiss army recruitment centres, which cover 21 of the 26 Swiss cantons. (A canton is a type of administrative division of a country and the Swiss cantons are semisovereign states.) Switzerland has a mandatory army recruitment process: virtually all young men are contacted at approximately 19 years of age for determination of their eligibility for military or civil service. Thus, not only individuals who were finally selected to serve in the army were enrolled in the study, but a virtually complete census of the Swiss male population in this age group was eligible. The participants filled in the questionnaire online or via mail and were rewarded with a voucher of 30 Swiss Francs (CHF).

The follow-up assessment was conducted approximately 15 months after the baseline measurement, and the participants were reimbursed with a similar voucher. The participants who filled in both questionnaires received an additional voucher (30 CHF). Between the assessments, the participants were invited twice to update their contact details online. Each of these two updates was rewarded with a voucher (5 $\mathrm{CHF}$ ) once the second questionnaire was completed.

The Ethics Committee for Clinical Research of Lausanne University Medical School approved the study (Protocol No. 15/07).

\section{Participants}

A total of 15,074 young men visited the recruitment centres. Among them, 1,829 (12.1\%) did not meet the research staff because they were sick (but not chronically ill), were randomly selected to participate in another study [22], or were not informed about the study by the military staff. These non-inclusions were random and should not have influenced the findings. More information about sampling and non-response can be found in Studer et al. [23]. Of the 13,245 conscripts informed about the study, 7,563 (57.1\%) provided consent for participation, and 5,990 of those (79.2 \%) completed the baseline questionnaire. The follow-up questionnaire was completed by 5,223 participants $(87.2 \%)$.

For the model of progression from no or occasional cigarette use at baseline to daily cigarette use at followup, we excluded 1,275 of the 5,990 individuals (21.3\%) because of daily cigarette use already at baseline and an additional 485 individuals (8.1\%) because of missing data, resulting in a final sample of 4,230 individuals. 


\section{Measures}

\section{Outcome variable: onset of daily cigarette use}

The participants indicating cigarette use during the previous 12 months were asked how often they usually smoke cigarettes. The possible answers ("every day", "5-6 days per week", "3-4 days per week”, "1-2 days per week”, "2-3 days per month", and "once per month or less") were dichotomised (daily vs. non-daily use). For the analysis of the onset of daily cigarette smoking, the sample included all the participants who used cigarettes less than daily or not at all at baseline. Among these participants, reporting daily cigarette smoking at follow-up was classified as the onset of cigarette use.

\section{Predictor variables}

All the predictor variables were measured at baseline.

Socio-demographics The socio-demographic predictors included age in years and the highest completed level of education divided into two categories: a lower educational level (compulsory education or vocational school training) and a higher educational level (upper secondary education, college and university degrees). Additional socio-demographic predictors included the housing situation (living alone, living with a parent or parents, living with a partner, living with friends or in an institution), the means of subsistence (own person, own person and other persons or institutions, other persons or institutions), living in a partnership (yes/no), and the number of siblings.

Religion and religiosity Religious denomination was assessed by the question "What is your religion (even if you do not practice or believe in God)?" with nine response categories, which we merged into four categories: Christian religion, Muslim religion, other religion, and no religion. To measure religiosity, we used the first question of the Religious Background and Behaviour Questionnaire (RBB) [24] with the response categories (1) "I believe in God and practice religion", (2) "I believe in God but do not practice religion", (3) "I do not know what to believe about God", (4) "I believe we cannot really know about God" (agnostic), or (5) "I do not believe in God" (atheist).

Health and health behaviour Physical and mental health were measured by the Physical Component Summary and the Mental Component Summary of the 12-Item Short-Form Health Survey (SF-12) [25], the Major Depression Inventory (MDI) [26], and the International Physical Activity Questionnaire (IPAQ) [27]. In a study using data from 9 different countries, correlations of both the Mental and the Physical Component Summary measures of the SF-12 and the SF-36 were between .94 and .97 [28].
Various studies have shown that the SF-36 is a valid and reliable measure of population health $[28,29]$. A study of the psychometric properties of the MDI indicated adequate internal and external validity (high correlation of 0.86 with the Hamilton Depression Scale) [26].

Social context The parental situation was assessed by a question derived from the Alcohol Use Disorder and Associated Disabilities Interview Schedule-IV (AUDADISIV) [30]. The parents' educational level was assessed and categorised analogous to the educational level of the study participant (see above). The financial situation of the family was measured with a question from the European School Survey Project on Alcohol and Other Drugs (ESPAD) [31]; this question uses a 7-point scale ("very much below average"- "very much above average") to assess how well off the individual's family is compared to other Swiss families.

Parenting was assessed by three variables used in the ESPAD. Two questions ("Before you were 18 years old, how satisfied were you usually with your relationship with (a) your mother and (b) your father?") measured the participants' retrospective satisfaction with the relationship with their parents on scales ranging from 1 ("very satisfied") to 5 ("not satisfied at all"). The scores were dichotomised at the median of the mean of the items assessing maternal and paternal relationships. Two questions with response scales ranging from 1 ("almost always") to 5 ("almost never") were used to derive parental regulation at the age of 15 years: "My parents set definite rules about what I was allowed to do (a) at home and (b) outside the home". The scores were averaged and dichotomised at the median. The retrospective assessment of parental knowledge of peers and the whereabouts at age 15 were derived by averaging and dichotomising the scores obtained from the responses to two five-point items: "My parents knew (a) whom I was with and (b) where I was in the evenings." Parental rule setting and knowledge of peers and the whereabouts was asked at around age 15 because this is the time when peer influences become stronger, and particularly meeting with friends without the participation of parent increases [32]. For example, the Study on Health Behaviour in School-Aged Children (HBSC) across 41 European countries showed that peer influences, such as being four or more days per week out with friends, increase strongly between the ages of 11 and 15 [33].

The lifetime prevalence of psychiatric, alcohol or drug problems in the parents was assessed separately for both parents. The participants indicated whether a significant problem had ever been present in one or several domains (i.e., psychiatric problem, alcohol problem, or drug problem). A similar question addressed previous significant alcohol, drug, or psychiatric problems in peers. Peer pressure 
was assessed by a shortened version of the Peer Pressure Inventory (PPI) [34].

Substance use Lifetime use of alcohol was assessed by the question "Did you have at least 12 alcoholic standard drinks in your entire life?" Examples for alcoholic standard drinks were pictured. Furthermore, the age of the first use of at least one standard alcoholic drink, the 12month prevalence, and at-risk drinking were assessed. The possible answers ("every day", "5-6 days per week", "3-4 days per week", "1-2 days per week", "2-3 days per month", "once per month or less") were dichotomised (daily vs. non-daily use). Participants who indicated 'yes' were classified by the Alcohol Use Disorders Identification Test (AUDIT-C) [35] as not at risk $($ score $<4$ ) or at risk drinkers (score $\geq 4$ ) [36]; participants who indicated 'no' were classified into the category 'no alcohol use in the previous 12 months'. In studies, which compared the AUDIT-C to other, more comprehensive screening instruments for alcohol use disorders, the AUDIT-C showed good sensitivity, specificity and positive predictive validity $[36,37]$.

To assess the lifetime use of cigarettes, participants indicated whether they consumed at least 50 cigarettes in their life. Furthermore, the age of first cigarette smoking and the 12-month prevalence of cigarette smoking were assessed (see above). Additionally, the 12-month prevalence for the use of tobacco products other than cigarettes (i.e., water pipes (shisha, smoked only with tobacco), snus, snuff, chewing tobacco, cigars/cigarillos, tobacco pipes) was measured.

The lifetime use of cannabis was assessed by asking "Have you ever consumed cannabis (grass, hashish, marihuana), more than just to try?" Subsequent questions measured the age of first cannabis use and problematic cannabis use, which was assessed with the Cannabis Use Disorders Identification Test (CUDIT) [38]. Although the internal consistency of the CUDIT seems appropriate (.72-.78), the predictive power of the instrument, tested in different studies, is mixed [39]. A cut-off value of 8 was used to discriminate problematic from non-problematic cannabis use.

The lifetime use of illicit drugs other than cannabis at baseline was assessed by a series of questions measuring the frequency of use of 15 illicit drugs within the course of the individual's life (e.g., hallucinogens, speed, amphetamines, crystal meth, poppers, ecstasy, cocaine/ crack/freebase, and heroin). The lifetime use of illicit drugs was defined as having used at least one of these substances at least once.

Personality Screening for adult attention deficit syndrome was performed with the Attention Deficit Syndrome Self Report Scale (ASRS-v1.1) [40]. Sensation seeking was measured by the Brief Sensation Seeking Scale (BSSS-8) [41]. In two studies, the BSSS-8 showed good internal consistencies $(\alpha=.76$ and $\alpha=.74)$ and was predictive of other risk and protective factors [42]. Aggression/hostility, sociability and neuroticism/anxiety were assessed by the corresponding subscales of the Zuckerman-Kuhlman Personality Scale (ZKPQ-50-cc) [43]. In a validation sturdy, this instrument showed good psychometric and structural properties in four different languages with alpha coefficients above .70 [44]. Peer pressure was assessed by a shortened version of the Peer Pressure Inventory (PPI), which showed acceptable testretest and inter-rater reliability in a study examining the perception of peer pressure [34]. The presence of an antisocial personality disorder (ASPD) was assessed by questions of the Mini International Neuropsychiatric Interview [45]. It involves two sections with six childhood criteria. If two of these criteria were positive, then the subjects were asked about six behaviours since age 15 . Three affirmative answers qualified for ASPD.

\section{Analyses}

Starting with separate logistic regression analyses (subsequently termed 'univariate analyses'), we evaluated the potential of each baseline variable to predict the onset of daily cigarette use. To reduce multicollinearity within the final multivariate model, we developed separate multivariate prediction models for each of the following categories of predictor variables: (1) socio-demographics, (2) religion and spirituality, (3) health and health behaviour, (4) social context, (5) substance use, and (6) personality. Variable selection comprised the following steps: (1) Significant predictors from the univariate analyses were entered into the separate models. (2) Variables that were not significant were removed manually one by one; variables with the highest p-values were removed first (backward selection). (3) To account for suppressor effects, the resulting models were verified by tentatively adding the excluded variables separately. Only significant variables were retained in the category-specific multivariate models (forward selection). Based on the results of these models, we developed one final model for the onset of daily cigarette use. Variable selection was conducted in an analogous way as described above, with the exception of including all significant predictors from the category-specific models at step (1). Nagelkerke's $R^{2}$ was calculated as a goodness-of-fit measure for all multivariate models. All the analyses were performed using SPSS version 20 [46], and $p<0.05$ was set as the significance level.

\section{Results}

\section{Sample characteristics}

The baseline characteristics of the 4,230 participants included in the analysis of the onset of daily cigarette 
Table 1 Baseline characteristics for individuals with and without the onset of cigarette use and univariate associations with the onset of daily cigarette use

\begin{tabular}{|c|c|c|c|c|c|c|c|}
\hline \multirow{2}{*}{$\begin{array}{l}\text { Variable categories and variables } \\
\text { Socio-demographics }\end{array}$} & \multicolumn{2}{|c|}{ No onset $n=3961$} & \multicolumn{2}{|c|}{ Onset $n=269$} & \multirow[t]{2}{*}{$O R$} & \multirow[t]{2}{*}{$(95 \%$ Cl) } & \multirow[t]{2}{*}{$P$} \\
\hline & & & & & & & \\
\hline Age in years, $M(S D)^{\text {a }}$ & 19.4 & $(1.2)$ & 19.4 & $(1.2)$ & 0.99 & $(0.89-1.10)$ & .827 \\
\hline Lower educational level (Ref) ${ }^{\text {b }}$ & 2,758 & $(70.9 \%)$ & 220 & $(82.7 \%)$ & & & \\
\hline Higher educational level & 1,132 & $(29.1 \%)$ & 46 & $(17.3 \%)$ & 0.51 & $(0.37-0.71)$ & $<.001$ \\
\hline Living with parent or parents (Ref) ${ }^{c}$ & 3,598 & $(91.5 \%)$ & 232 & $(86.6 \%)$ & & & \\
\hline Living alone & 98 & $(2.5 \%)$ & 10 & (3.7\%) & 1.58 & $(0.82-3.07)$ & .175 \\
\hline Living with partner & 87 & $(2.2 \%)$ & 9 & $(3.4 \%)$ & 1.60 & $(0.80-3.23)$ & .185 \\
\hline Living with friends or in institution & 151 & $(3.8 \%)$ & 17 & $(6.3 \%)$ & 1.75 & $(1.04-2.93)$ & .035 \\
\hline Means of subsistence: own person (Ref) ${ }^{d}$ & 776 & $(19.7 \%)$ & 58 & $(21.7 \%)$ & & & \\
\hline Own person and others persons or institutions & 1,643 & $(41.6 \%)$ & 129 & $(48.3 \%)$ & 1.06 & $(0.77-1.46)$ & .739 \\
\hline Other persons or institutions & 1,522 & $(38.7 \%)$ & 80 & $(30.0 \%)$ & 0.70 & $(0.50-0.997)$ & .048 \\
\hline Not living in a partnership (Ref) ${ }^{\mathrm{e}}$ & 3,767 & $(95.8 \%)$ & 251 & $(94.0 \%)$ & & & \\
\hline Living in a partnership & 166 & $(4.2 \%)$ & 16 & $(6.0 \%)$ & 1.45 & $(0.85-2.45)$ & .171 \\
\hline Having no siblings (Ref) ${ }^{f}$ & 243 & $(6.3 \%)$ & 20 & $(7.7 \%)$ & & & \\
\hline One or two siblings & 2,938 & $(76.6 \%)$ & 195 & $(75.3 \%)$ & 0.81 & $(0.50-1.30)$ & .378 \\
\hline Three or more siblings & 656 & $(17.1 \%)$ & 44 & $(17.0 \%)$ & 0.82 & $(0.47-1.14)$ & .465 \\
\hline \multicolumn{8}{|l|}{ Religion and spirituality } \\
\hline Christian religion (Ref) ${ }^{g}$ & 2,949 & $(75.5 \%)$ & 176 & (66.9\%) & & & \\
\hline Muslim religion & 142 & $(3.6 \%)$ & 10 & $(3.8 \%)$ & 1.18 & $(0.61-2.28)$ & .623 \\
\hline Other religion & 87 & $(2.2 \%)$ & 6 & $(2.3 \%)$ & 1.16 & $(0.50-2.68)$ & .736 \\
\hline No religion & 727 & $(18.6 \%)$ & 71 & $(27.0 \%)$ & 1.64 & $(1.23-2.18)$ & .001 \\
\hline Atheist (Ref) ${ }^{h}$ & 1,025 & $(26.3 \%)$ & 86 & $(32.6 \%)$ & & & \\
\hline Agnostic & 670 & $(17.2 \%)$ & 44 & $(16.7 \%)$ & 0.78 & $(0.54-1.14)$ & .202 \\
\hline Unsure what to think about god & 491 & $(12.6 \%)$ & 37 & $(14.0 \%)$ & 0.90 & $(0.60-1.34)$ & .599 \\
\hline Believe in god but not practicing & 1,201 & $(30.8 \%)$ & 77 & $(29.2 \%)$ & 0.76 & $(0.56-1.05)$ & .098 \\
\hline Believe in god and practicing & 516 & $(13.2 \%)$ & 20 & $(7.6 \%)$ & 0.46 & $(0.28-0.76)$ & .002 \\
\hline \multicolumn{8}{|l|}{ Health and health behaviour } \\
\hline Physical health (SF-12, scale 0-100), M (SD) ${ }^{\mathrm{i}}$ & 55.2 & $(5.0)$ & 54.8 & $(5.2)$ & 0.98 & $(0.96-1.01)$ & .133 \\
\hline Mental health (SF-12, scale 0-100), M (SD) ${ }^{\mathrm{j}}$ & 49.9 & $(8.4)$ & 49.2 & $(9.0)$ & 0.99 & $(0.98-1.01)$ & .220 \\
\hline Depression (MDI, scale 0-50), M (SD) ${ }^{k}$ & 6.6 & $(6.7)$ & 8.0 & $(8.0)$ & 1.03 & $(1.01-1.04)$ & .001 \\
\hline Low physical activity (IPAQ) (Ref) ' & 355 & $(9.6 \%)$ & 19 & $(7.8 \%)$ & & & \\
\hline Moderate physical activity & 953 & $(25.9 \%)$ & 60 & $(24.7 \%)$ & 1.18 & $(0.69-2.00)$ & .548 \\
\hline High physical activity & 2,371 & $(64.4 \%)$ & 164 & $(67.5 \%)$ & 1.29 & $(0.79-2.11)$ & .303 \\
\hline \multicolumn{8}{|l|}{ Social context } \\
\hline Grew up with both parents (Ref) ${ }^{m}$ & 3,181 & $(81.2 \%)$ & 185 & $(70.1 \%)$ & & & \\
\hline ...with parent and step-parent & 185 & $(4.7 \%)$ & 29 & $(11.0 \%)$ & 2.70 & $(1.77-4.10)$ & $<.001$ \\
\hline ...with one parent & 500 & $(12.8 \%)$ & 47 & $(17.8 \%)$ & 1.62 & $(1.16-2.26)$ & .005 \\
\hline ... with adoptive or foster parents or in institution & 51 & $(1.3 \%)$ & 3 & $(1.1 \%)$ & 1.01 & $(0.31-3.27)$ & .985 \\
\hline No parental divorce before the age of 18 (Ref) ${ }^{n}$ & 3,066 & $(78.4 \%)$ & 183 & $(69.6 \%)$ & & & \\
\hline Parental divorce before the age of 18 & 846 & $(21.6 \%)$ & 80 & $(30.4 \%)$ & 1.58 & $(1.21-2.08)$ & .001 \\
\hline Lower educational level of the father (Ref) ${ }^{\circ}$ & 1,998 & $(51.2 \%)$ & 133 & $(50.6 \%)$ & & & \\
\hline Higher educational level of the father & 1,904 & $(48.8 \%)$ & 130 & (49.4\%) & 1.03 & $(0.80-1.32)$ & .842 \\
\hline
\end{tabular}


Table 1 Baseline characteristics for individuals with and without the onset of cigarette use and univariate associations with the onset of daily cigarette use (Continued)

\begin{tabular}{|c|c|c|c|c|c|c|c|}
\hline Lower educational level of the mother (Ref) ${ }^{P}$ & 2,241 & $(57.6 \%)$ & 157 & $(59.5 \%)$ & & & \\
\hline Higher educational level of the mother & 1,653 & $(42.4 \%)$ & 107 & $(40.5 \%)$ & 0.92 & $(0.71-1.19)$ & .541 \\
\hline Financial situation of family (scale $1-7), M(S D)^{a}$ & 3.56 & $(1.0)$ & 3.6 & $(1.0)$ & 1.04 & $(0.92-1.19)$ & .504 \\
\hline Good relationship with parents before age 18 , (Ref) ${ }^{r}$ & 3,217 & $(81.4 \%)$ & 199 & $(74.3 \%)$ & & & \\
\hline Bad relationship with parents before age of 18 & 733 & $(81.4 \%)$ & 69 & $(74.3 \%)$ & 1.52 & $(1.14-2.03)$ & .004 \\
\hline Lower parental rule setting at age 15 (Ref) ${ }^{\mathrm{s}}$ & 1,550 & $(39.3 \%)$ & 121 & $(45.3 \%)$ & & & \\
\hline Higher parental rule setting at age 15 & 2,398 & $(60.7 \%)$ & 145 & $(54.7 \%)$ & 0.78 & $(0.61-1.001)$ & .051 \\
\hline Lower parental monitoring at age 15 (Ref) ${ }^{\mathrm{t}}$ & 902 & $(22.8 \%)$ & 74 & $(27.8 \%)$ & & & \\
\hline Higher parental monitoring at age 15 & 3,046 & $(77.2 \%)$ & 192 & $(72.2 \%)$ & 0.77 & $(0.58-1.02)$ & .063 \\
\hline No psychiatric problem in the father (Ref) ${ }^{u}$ & 3,697 & $(93.9 \%)$ & 246 & $(91.4 \%)$ & & & \\
\hline Psychiatric problem in the father & 241 & $(6.1 \%)$ & 23 & $(8.6 \%)$ & 1.43 & $(0.92-2.24)$ & .114 \\
\hline No psychiatric problem in the mother (Ref) ${ }^{\vee}$ & 3,783 & $(96.1 \%)$ & 252 & $(93.7 \%)$ & & & \\
\hline Psychiatric problem in the mother & 154 & $(3.9 \%)$ & 17 & $(6.3 \%)$ & 1.66 & $(0.99-2.78)$ & .055 \\
\hline No psychiatric problem in peers (Ref) ${ }^{w}$ & 2,398 & $(61.4 \%)$ & 116 & $(43.8 \%)$ & & & \\
\hline Psychiatric problem in peers & 1,507 & $(38.6 \%)$ & 149 & $(56.2 \%)$ & 2.04 & $(1.59-2.63)$ & $<.001$ \\
\hline \multicolumn{8}{|l|}{ Substance use } \\
\hline Never used $\geq 50$ cigarettes $^{x}$ & 3,169 & $(80.0 \%)$ & 65 & $(24.2 \%)$ & 12.56 & $(9.40-16.78)$ & $<.001$ \\
\hline Lifetime use of $\geq 50$ cigarettes & 792 & $(20.0 \%)$ & 204 & $(75.8 \%)$ & & & \\
\hline Age of first cigarette smoking, $M(S D)^{y}$ & 15.1 & $(2.4)$ & 14.7 & $(2.9)$ & 0.94 & $(0.90-0.99)$ & .026 \\
\hline No use of cigarettes (previous 12 months) (Ref) ${ }^{z}$ & 2,774 & $(70.0 \%)$ & 50 & $(18.6 \%)$ & & & \\
\hline Occasional (non-daily) cigarette use & 1,187 & $(30.0 \%)$ & 219 & $(81.4 \%)$ & 10.24 & $(7.47-14.02)$ & $<.001$ \\
\hline No use of tobacco product other than cigarettes (previous 12 months) (Ref) ${ }^{\text {aa }}$ & 2,189 & $(55.3 \%)$ & 68 & $(25.3 \%)$ & & & \\
\hline Use of tobacco product other than cigarettes & 1,772 & $(44.7 \%)$ & 201 & $(74.7 \%)$ & 3.65 & $(2.75-4.84)$ & $<.001$ \\
\hline Never used $\geq 12$ alcoholic drinks ab & 421 & $(11.1 \%)$ & 13 & $(4.9 \%)$ & & & \\
\hline Lifetime use of $\geq 12$ alcoholic drinks & 3,366 & $(88.9 \%)$ & 250 & $(95.1 \%)$ & 2.35 & $(1.33-4.13)$ & .003 \\
\hline Age of first drink, $M(S D)^{\text {ac }}$ & 14.6 & $(1.9)$ & 14.0 & $(2.03)$ & 0.87 & $(0.83-0.92)$ & $<.001$ \\
\hline Alcohol use — no use or not at-risk (AUDIT-C) (previous 12 months) (Ref) ad & 1,374 & $(35.0 \%)$ & 58 & $(21.8 \%)$ & & & \\
\hline Alcohol use-at-risk & 2,550 & $(65.0 \%)$ & 208 & $(78.2 \%)$ & 1.93 & $(1.43-2.60)$ & $<.001$ \\
\hline Never used cannabis ae & 1,433 & $(36.2 \%)$ & 194 & $(72.1 \%)$ & & & \\
\hline Lifetime use of cannabis & 2,522 & $(63.8 \%)$ & 75 & $(27.9 \%)$ & 4.55 & $(3.46-5.99)$ & $<.001$ \\
\hline Age of first cannabis use, $M(S D)^{\text {af }}$ & 16.2 & $(1.8)$ & 15.6 & $(2.1)$ & 0.84 & $(0.77-0.90)$ & $<.001$ \\
\hline No cannabis use (previous 12 months) (Ref) ${ }^{\text {ag }}$ & 3,125 & $(18.9 \%)$ & 119 & $(44.2 \%)$ & & & \\
\hline No problem use (CUDIT) & 701 & $(17.7 \%)$ & 95 & $(35.3 \%)$ & 3.56 & $(2.69-4.72)$ & $<.001$ \\
\hline Problem use (CUDIT) & 134 & $(3.4 \%)$ & 55 & $(20.4 \%)$ & 10.78 & $(7.50-15.50)$ & $<.001$ \\
\hline Never used illicit drugs other than cannabis (Ref) ${ }^{\text {ah }}$ & 3,517 & $(89.7 \%)$ & 181 & $(68.0 \%)$ & & & \\
\hline Lifetime use of illicit drugs other than cannabis & 406 & $(10.3 \%)$ & 85 & $(32.0 \%)$ & 1.07 & $(3.08-5.37)$ & $<.001$ \\
\hline \multicolumn{8}{|l|}{ Personality } \\
\hline No attention deficit syndrome (ASRS) (Ref) ai & 3,820 & $(96.6 \%)$ & 257 & $(95.9 \%)$ & & & \\
\hline Attention deficit syndrome & 135 & $(3.4 \%)$ & 11 & $(4.1 \%)$ & 1.21 & $(0.65-2.27)$ & .550 \\
\hline Sensation seeking (BSSS total score, range 1-5), M (SD) aj & 3.0 & $(0.8)$ & 3.3 & $(0.9)$ & 1.56 & $(1.34-1.82)$ & $<.001$ \\
\hline Aggression (ZKPQ, subscale, range $0-10), M(S D)^{\text {ak }}$ & 4.0 & $(2.2)$ & 4.6 & $(2.1)$ & 1.13 & $(1.07-1.20)$ & $<.001$ \\
\hline Sociability (ZKPQ, subscale, range $0-10), M(S D)$ al & 5.7 & $(2.3)$ & 6.4 & (1.9) & 1.15 & $(1.09-1.22)$ & $<.001$ \\
\hline
\end{tabular}


Table 1 Baseline characteristics for individuals with and without the onset of cigarette use and univariate associations with the onset of daily cigarette use (Continued)

\begin{tabular}{|c|c|c|c|c|c|c|c|}
\hline Anxiety (ZKPQ, subscale, range $0-10), M(S D)^{\text {am }}$ & 1.9 & $(1.9)$ & 2.0 & $(2.0)$ & 1.02 & $(0.95-1.08)$ & .636 \\
\hline Peer pressure (PPI total score, range $-3-+3), M(S D)$ an & 0.3 & $(0.4)$ & 0.4 & $(0.4)$ & 1.46 & $(1.06-2.00)$ & .020 \\
\hline No anti-social personality disorder (Ref) ${ }^{\text {ao }}$ & 3,429 & $(87.6 \%)$ & 196 & $(74.5 \%)$ & & & \\
\hline Anti-social personality disorder & 484 & $(12.4 \%)$ & 67 & $(25.5 \%)$ & 2.42 & $(1.81-3.25)$ & $<.001$ \\
\hline
\end{tabular}

Separate binary logistic regression model for each baseline variable. Values are $\mathrm{n}$ (\%) unless stated otherwise. Missing values: ${ }^{\mathrm{a}} n=1,{ }^{\mathrm{b}} n=74,{ }^{\mathrm{c}} n=28,{ }^{\mathrm{d}} n=31$, ${ }^{\mathrm{e}} n=30,{ }^{\mathrm{f}} n=134,{ }^{\mathrm{g}} n=62,{ }^{\mathrm{h}} n=63,{ }^{\mathrm{i}} n=29,{ }^{\mathrm{j}} n=29,{ }^{\mathrm{k}} n=42,{ }^{\mathrm{l}} n=308,{ }^{\mathrm{m}} n=49,{ }^{\mathrm{n}} n=55,{ }^{\mathrm{o}} n=65,{ }^{\mathrm{p}} n=72,{ }^{\mathrm{a}} n=31,{ }^{\mathrm{r}} n=12,{ }^{\mathrm{s}} n=15,{ }^{\mathrm{t}} n=16,{ }^{\mathrm{u}} n=23,{ }^{\mathrm{v}} n=24,{ }^{\mathrm{w}} n=60,{ }^{\mathrm{x}} n=0$, ${ }^{\mathrm{y}} n=2028,{ }^{\mathrm{z}} n=0,{ }^{\mathrm{aa}} n=0,{ }^{\mathrm{ab}} n=6,{ }^{\mathrm{ac}} n=175,{ }^{\mathrm{ad}} n=40,{ }^{\mathrm{ae}} n=6,{ }^{\mathrm{af}} n=2,605,{ }^{\mathrm{ag}} n=1,{ }^{\mathrm{ah}} n=41,{ }^{\mathrm{ai}} n=7,{ }^{\mathrm{aj}} n=3,{ }^{\mathrm{ak}} n=5,{ }^{\mathrm{a}} n=5,{ }^{\mathrm{am}} n=5,{ }^{\mathrm{a}} n=81,{ }^{\mathrm{a}} n=54$ ASRS Item Screener of the Attention Deficit Syndrome Self Report Scale, AUDIT-C Alcohol Use Disorders Identification Test-Consumption, BSSS Brief Sensation Seeking Scale, CI confidence interval, CUDIT Cannabis Use Disorder Identification Test, IPAQ International Physical Activity Questionnaire, $M$ mean, MDI Major Depressive Inventory, OR Odds Ratio, PPI Peer Pressure Inventory, Ref reference category, SD standard deviation, SF-12 Short-Form Health Survey, ZKPQ Zuckerman-Kuhlman Personality Questionnaire

smoking are displayed in Table 1. At baseline, 2,824 $(66.8 \%)$ participants reported no cigarette use during the preceding 12 months, whereas 1,406 (33.2\%) participants had smoked cigarettes occasionally. Among them, 216 (5.1\%) participants smoked five or six days per week, 139 (3.3\%) participants smoked three or four days per week, and 202 (4.8\%) participants smoked two or three days per month. Furthermore, 240 (5.7 \%) participants had smoked cigarettes two or three days per month, and 609 (14.4\%) participants smoked monthly or less often.

\section{Predictors of the onset of daily tobacco use}

Between baseline and follow-up, 269 (6.4\%) participants progressed to daily cigarette smoking. Table 1 shows the results of the separate logistic regression analyses indicating individual associations between predictors and the onset of cigarette use. Table 2 presents the categoryspecific models and the final model. According to the final model, having used cannabis and/or having occasionally smoked cigarettes during the 12 months before baseline, and a lifetime use of more than 50 cigarettes were associated with a progression to daily cigarette use. Beyond substance use, the following variables predicted a higher probability of progression to daily cigarette use: a lower educational level, having no religious affiliation (as opposed to Christian religion), having grown up with only one parent and a step-parent (as opposed to both parents), having had peers with psychiatric problems, and a higher sociability. All the variables included in the final model explain $27.9 \%$ of the variance. The group of variables related to substance use represented the strongest predictors, with a variance explanation of $25.1 \%$.

\section{Discussion}

This study aimed to examine the role of cannabis use in the progression of tobacco use, as previously investigated in several studies dedicated to the reverse gateway hypothesis $[3-5,47]$. Compared to previous studies, we accounted for a broad range of predictor variables, including variables that have not been previously studied in this context, e.g., religiosity and several personality dimensions. With regard to the onset of daily cigarette smoking, cannabis use, i.e., more pronounced cannabis use disorder symptoms according to the CUDIT, remained among the strongest predictors aside from the lifetime use of more than 50 cigarettes and occasional cigarette use. This strong association between cannabis and tobacco use may be partially explained by the fact that more than $90 \%$ of the Swiss cannabis users smoke it mixed with tobacco [15]. Thus, in line with previous qualitative [10] and quantitative findings [7], our results suggest that the way of administration of cannabis and tobacco, particularly smoking cannabis joints mixed with tobacco, plays an important role in young adults' onset of daily cigarette use, making these findings particularly relevant for countries in which cannabis is mainly co-administered with tobacco. Moreover, we found that the use of tobacco products other than cigarettes (i.e., water pipes (shisha, smoked only with tobacco), snus, snuff, chewing tobacco, cigars/cigarillos, and tobacco pipes) played a less important role than cannabis use for the onset of daily cigarette use. This is in line with the study of Agrawal and Lynskey [7] in which smoking tobacco was significantly associated with cannabis use and dependence whereas the use of smokeless tobacco was not.

In our study, the factors referring to a genetic vulnerability such as a psychiatric disorder of the father/mother or externalizing and/or delinquent personality traits (antisocial personality, aggression, sensation seeking, and attention deficit syndrome) did not remain significant in the overall predictor model. This is in line with the conclusion of Ramo and colleagues [48] who found in their systematic literature review that not genetic but environmental factors appear to account for the largest variance in the couse of tobacco and cannabis. Although we did not assess peers' substance use and delinquency as an explaining factor [19], in our models for the onset of daily cigarette smoking the psychiatric problems of peers at age 15 were still of higher relevance than genetic factors. Similarly, to grow up with one parent and step-parent remained as a further context factor in the overall model. More specific socio-economic factors or factors indicating a change of 
Table 2 Multivariate associations between baseline variables and the onset of daily cigarette use

\begin{tabular}{|c|c|c|c|c|}
\hline \multirow[t]{2}{*}{ Variable categories and variables } & \multicolumn{2}{|c|}{ Category-specific models } & \multicolumn{2}{|l|}{ Overall model } \\
\hline & OR $(95 \%$ Cl) & $p$ & $O R(95 \% C l)$ & p \\
\hline \multicolumn{5}{|l|}{ Socio-demographics } \\
\hline \multicolumn{5}{|l|}{ Lower educational level (Ref) } \\
\hline Higher educational level & $0.51(0.37-0.71)$ & $<.001$ & $0.45(0.32-0.65)$ & $<.001$ \\
\hline \multicolumn{5}{|l|}{ Living with parent or parents (Ref) } \\
\hline Living alone & $1.45(0.72-2.92)$ & .294 & & \\
\hline Living with partner & $1.69(0.84-3.41)$ & .144 & & \\
\hline Living with friends or in institution & $2.25(1.32-3.84)$ & .003 & & \\
\hline \multicolumn{5}{|l|}{ Religion and spirituality } \\
\hline \multicolumn{5}{|l|}{ Christian religion (Ref) } \\
\hline Muslim religion & $1.40(0.71-2.73)$ & .332 & $1.53(0.74-3.17)$ & .250 \\
\hline Other religion & $1.26(0.54-2.92)$ & .579 & $1.01(0.40-2.56)$ & .982 \\
\hline No religion & $1.48(1.09-2.01)$ & .013 & $1.42(1.03-1.97)$ & .035 \\
\hline \multicolumn{5}{|l|}{ Atheist (Ref) } \\
\hline Agnostic & $0.85(0.58-1.25)$ & .410 & & \\
\hline Unsure what to think about god & $0.995(0.66-1.50)$ & .983 & & \\
\hline Believe in god but not practicing & $0.86(0.61-1.21)$ & .393 & & \\
\hline Believe in god and practicing & $0.49(0.29-0.84)$ & .010 & & \\
\hline \multicolumn{5}{|l|}{ Health and health behaviour } \\
\hline Depression (MDI, scale 0-50) & $1.03(1.01-1.04)$ & .001 & & \\
\hline \multicolumn{5}{|l|}{ Social context } \\
\hline \multicolumn{5}{|l|}{ Grew up with both parents (Ref) } \\
\hline ...with parent and step-parent & $2.60(1.71-3.96)$ & $<.001$ & $2.16(1.34-3.49)$ & .002 \\
\hline ...with one parent & $1.57(1.12-2.20)$ & .008 & $1.27(0.87-1.85)$ & .214 \\
\hline ... with adoptive or foster parents or in institution & $0.95(0.29-3.08)$ & .928 & $0.71(0.21-2.43)$ & .583 \\
\hline \multicolumn{5}{|l|}{ No psychiatric problem in peer/s at age of 15 (Ref) } \\
\hline Psychiatric problem in peer/s at age of 15 & $1.97(1.53-2.54)$ & $<.001$ & $1.35(1.02-1.78)$ & .038 \\
\hline \multicolumn{5}{|l|}{ Substance use } \\
\hline \multicolumn{5}{|l|}{ Never used $\geq 50$ cigarettes } \\
\hline Lifetime use of $\geq 50$ cigarettes & $4.88(3.37-7.08)$ & $<.001$ & $4.22(2.89-6.16)$ & $<.001$ \\
\hline \multicolumn{5}{|l|}{ No use of cigarettes during previous 12 months } \\
\hline Occasional (non-daily) cigarette use & $3.02(2.01-4.54)$ & $<.001$ & $3.02(1.99-4.58)$ & $<.001$ \\
\hline \multicolumn{5}{|l|}{ No cannabis use (previous 12 months) (Ref) } \\
\hline No problem use (CUDIT) & $1.41(1.03-1.92)$ & .031 & $1.52(1.10-2.09)$ & .011 \\
\hline Problem use (CUDIT) & $3.00(2.02-4.47)$ & $<.001$ & $3.06(2.00-4.67)$ & $<.001$ \\
\hline \multicolumn{5}{|l|}{ Personality } \\
\hline Sensation seeking (BSSS total score, range 1-5), M (SD) & $1.36(1.15-1.60)$ & $<.001$ & & \\
\hline Aggression (ZKPQ, subscale, range $0-10)$ & $1.07(1.01-1.14)$ & .025 & & \\
\hline Sociability (ZKPQ, subscale, range $0-10)$ & $1.12(1.06-1.19)$ & $<.001$ & $1.12(1.04-1.20)$ & .002 \\
\hline \multicolumn{5}{|l|}{ No anti-social personality disorder (Ref) } \\
\hline Anti-social personality disorder & $1.84(1.33-2.52)$ & $<.001$ & & \\
\hline
\end{tabular}

Nagelkerke's $R^{2}$ : overall model: 0.279 , demographics: 0.018 , religion and spirituality: 0.012 , health and health behaviour: 0.006 , social context: 0.032 , substance use: 0.251 , personality: 0.046 BSSS Brief Sensation Seeking Scale, CI confidence interval, CUDIT Cannabis Use Disorder Identification Test, MDI Major Depressive Inventory, OR Odds Ratio, Ref reference category, ZKPQ Zuckerman-Kuhlman Personality Questionnaire 
these [21] during adolescence did not enter the overall model.

Among the religion and spirituality factors, having no religion was a relevant predictor for the onset of daily cigarette smoking. Whether substantial gains or losses in religiosity from childhood to adulthood occurred, a predictor that has been reported to be associated with substance use and misuse in the general U.S. population [20], was not assessed in our study. In line with Agrawal et al. [11], to believe in God and to practice religion was the other significant predictor in the category-specific religion and spirituality model, but this variable did not enter the overall predictor model.

Considering the amount of variance explained by the category-specific models, substance abuse explained the major part of variance $(25.1 \%)$ compared to the other categories $(0.6 \%$ to $4.6 \%)$.

One limitation of this study is that the participants were only observed for a relatively short time period because they were reassessed at one time point after 15 months. In addition, there was a period of approximately three months that was not included in the assessments because the follow-up assessment only examined the preceding 12 months. In order to analyse potential moderators and mediators in the reverse gateway scenario, cohort studies including multiple assessments over a longer time period are required. A further limitation is the dichotomized outcome variable (daily cigarette smoking vs. non-daily cigarette smoking). This implicates that a group of 216 smokers who smoked cigarettes on 5 to 6 days a week already at baseline were treated as nondaily smokers and therefore includes in the analysis. These occasional smokers may have had a particularly high chance to proceed to daily cigarette smoking and to be treated as participants with "onset of daily cigarette smoking" which may seem an artificial transition, given they already smoked already nearly daily at baseline.

\section{Conclusions}

According to our findings, appropriate interventions to prevent young adults from daily cigarette use should specifically address occasional cigarette smokers and users of cannabis that mix and smoke these substances together.

\footnotetext{
Abbreviations

ASRS: Item Screener of the Attention Deficit Syndrome Self Report Scale; AUDIT-C: Alcohol Use Disorders Identification Test-Consumption; BSSS: Brief Sensation Seeking Scale; C-SURF: Cohort Study on Substance Use Risk Factors; CUDIT: Cannabis Use Disorder Identification Test; IPAQ: International Physical Activity Questionnaire; MDI: Major Depressive Inventory; PPI: Peer Pressure Inventory; Ref: reference category; SF-12: Short-Form Health Survey; ZKPQ: Zuckerman-Kuhlman Personality Questionnaire.
}

\section{Competing interests}

The authors declare that they have no competing interests.

\section{Authors' contributions}

MPS, SH and GM were responsible for the study design. JB and SH were responsible for the data management and data analysis. All authors read and approved the final manuscript.

\section{Acknowledgements}

This work was supported by Grant FN 33CSC0-122679 and Grant FN 33CS30_139467 from the Swiss National Research Foundation.

\section{Author details}

${ }^{1}$ Swiss Research Institute for Public Health and Addiction ISGF, University of Zurich, Konradstrasse 32, CH-8031 Zurich, Switzerland. ${ }^{2}$ Alcohol Treatment Centre, Lausanne University Hospital CHUV, Rue du Bugnon 21, CH-1011 Lausanne, Switzerland. ${ }^{3}$ Addiction Switzerland, Av. Louis-Ruchonnet 14, $\mathrm{CH}-1003$ Lausanne, Switzerland. ${ }^{4}$ Centre for Addiction and Mental Health, Toronto, Ontario, Canada. ${ }^{5}$ University of the West of England, Bristol, UK.

Received: 12 March 2015 Accepted: 27 August 2015

Published online: 02 September 2015

\section{References}

1. Lim SS, Vos T, Flaxman AD, Danaei G, Shibuya K, Adair-Rohani H, et al. A comparative risk assessment of burden of disease and injury attributable to 67 risk factors and risk factor clusters in 21 regions, 1990-2010: a systematic analysis for the Global Burden of Disease Study 2010. Lancet. 2012;380:2224-60.

2. Bentler PM, Newcomb MD, Zimmerman MA. Cigarette use and drug use progression. Growth trajectory and lagged effect hypotheses. In: Kandel DB, editor. Stages and pathways of drug involvement. Examining the gateway hypothesis. Cambridge: Cambridge University Press; 2002. p. 223-53.

3. Tullis LM, DuPont R, Frost-Pineda K, Gold MS. Marijuana and tobacco: a major connection? J Addict Dis. 2003;22:51-62.

4. Patton GC, Coffey C, Carlin JB, Sawyer SM, Lynskey M. Reverse gateways? Frequent cannabis use as a predictor of tobacco initiation and nicotine dependence. Addiction. 2005;100:1518-25.

5. Agrawal A, Madden PAF, Bucholz KK, Heath AC, Lynskey MT. Transitions to regular smoking and to nicotine dependence in women using cannabis. Drug Alcohol Depend. 2008;95:107-14.

6. Timberlake DS, Haberstick BC, Hopfer CJ, Bricker J, Sakai JT, Lessem JM, et al. Progression from marijuana use to daily smoking and nicotine dependence in a national sample of U.S. adolescents. Drug Alcohol Depend. 2007:88:272-81.

7. Agrawal A, Lynskey MT. Tobacco and cannabis co-occurrence: does route of administration matter? Drug Alcohol Depend. 2009;99:240-7.

8. Agrawal A, Silberg JL, Lynskey MT, Maes HH, Eaves LJ. Mechanisms underlying the lifetime co-occurrence of tobacco and cannabis use in adolescent and young adult twins. Drug Alcohol Depend. 2010;108:49-55.

9. Agrawal A, Madden PAF, Martin NG, Lynskey MT. Do early experiences with cannabis vary in cigarette smokers? Drug Alcohol Depend. 2013;128:255-9.

10. Amos A, Wiltshire S, Bostock Y, Haw S, McNeill A. "You can"t go without a fag... you need it for your hash' - a qualitative exploration of smoking, cannabis and young people. Addiction. 2004;99:77-81.

11. Agrawal A, Lynskey MT. Correlates of later-onset cannabis use in the National Epidemiological Survey on Alcohol and Related Conditions (NESARC). Drug Alcohol Depend. 2009;105:71-5.

12. Viveros M-P, Marco EM, File SE. Nicotine and cannabinoids: parallels, contrasts and interactions. Neurosci Biobehav Rev. 2006:30:1161-81.

13. Penetar DM, Kouri EM, Gross MM, McCarthy EM, Rhee CK, Peters EN, et al. Transdermal nicotine alters some of marihuana's effects in male and female volunteers. Drug Alcohol Depend. 2005;79:211-23.

14. Australian Institute of Health and Welfare. 2007 National Drug Strategy Household Survey: Detailed Findings. Drug Statistics Series No. 22. Cat. No. PHE 107. Volume AlHW cat. Canberra: AlHW; 2008:i-xii

15. Baggio S, Deline S, Studer J, Mohler-Kuo M, Daeppen J-B, Gmel G. Routes of administration of cannabis used for nonmedical purposes and associations with patterns of drug use. J Adolesc Heal. 2014;54:235-40.

16. Lipperman-Kreda S, Lee JP, Morrison C, Freisthler B. Availability of tobacco products associated with use of marijuana cigars (blunts). Drug Alcohol Depend. 2014;134:337-42. 
17. Richter KP, Kaur H, Resnicow K, Nazir N, Mosier MC, Ahluwalia JS. Cigarette smoking among marijuana users in the United States. Subst Abus. 2005;25:35-43.

18. Van Leeuwen AP, Verhulst FC, Reijneveld SA, Vollebergh WAM, Ormel J, Huizink AC. Can the gateway hypothesis, the common liability model and/ or, the route of administration model predict initiation of cannabis use during adolescence? A survival analysis-the TRAILS study. J Adolesc Heal. 2011:48:73-8.

19. Lynskey MT, Fergusson DM, Horwood LJ. The origins of the correlations between tobacco, alcohol, and cannabis use during adolescence. J Child Psychol Psychiatry. 1998;39:995-1005.

20. Moscati A, Mezuk B. Losing faith and finding religion: religiosity over the life course and substance use and abuse. Drug Alcohol Depend. 2014;136:127-34

21. Bowes L, Chollet A, Fombonne E, Galéra C, Melchior M. Lifecourse SEP and tobacco and cannabis use. Eur J Public Health. 2013;23:322-7.

22. Mohler-Kuo M, Wydler H, Zellweger U, Gutzwiller F. Differences in health status and health behaviour among young Swiss adults between 1993 and 2003. Swiss Med Wkly. 2006;136:464-72.

23. Studer J, Baggio S, Mohler-Kuo M, Dermota P, Gaume J, Bertholet N, et al. Examining non-response bias in substance use research-Are late respondents proxies for non-respondents? Drug Alcohol Depend. 2013;132:316-23.

24. Connors GJ, Tonigan JS, Miller WR. A measure of religious background and behavior for use in behavior change research. Psychol Addict Behav. 1996;10:90-6.

25. Gandek B, Ware JE, Aaronson NK, Apolone G, Bjorner JB, Brazier JE, et al. Cross-validation of item selection and scoring for the SF-12 Health Survey in nine countries: results from the IQOLA Project. J Clin Epidemiol. 1998:51:1171-8.

26. Olsen LR, Jensen DV, Noerholm V, Martiny K, Bech P. The internal and external validity of the Major Depression Inventory in measuring severity of depressive states. Psychol Med. 2003:33:351-6.

27. Craig $C L$, Marshall AL, Sjostrom M, Bauman AE, Booth ML, Ainsworth BE, et al. International physical activity questionnaire: 12-country reliability and validity. Med Sci Sports Exerc. 2003;35:1381-95.

28. McHorney CA, Ware JE, Raczek AE. The MOS 36-Item Short-Form Health Survey (SF-36): II. Psychometric and clinical tests of validity in measuring physical and mental health constructs. Med Care. 1993;31:247-63.

29. Hemingway $H$, Stafford M, Stansfeld S, Shipley M, Marmot M. Is the SF-36 a valid measure of change in population health? Results from the Whitehall II Study. Br Med J. 1997;315:1273-9.

30. Grant BF, Dawson DA, Stinson FS, Chou PS, Kay W, Pickering R. The Alcohol Use Disorder and Associated Disabilities Interview Schedule-IV (AUDADIS-IV): reliability of alcohol consumption, tobacco use, family history of depression and psychiatric diagnostic modules in a general population sample. Drug Alcohol Depend. 2003;71:7-16.

31. Hibell B, Guttormsson U, Ahlström S, Balakireva O, Bjarnason T, Kokkevi A Kraus L. The 2011 ESPAD Report. Substance Use among Students in 36 European Countries. Stockholm: CAN; 2012

32. Coleman JC. The Nature of Adolescence. 4th ed. London and New York: Routledge, Psychology Press; 2011.

33. Currie C, Zanotti C, Morgan A, Currie D, de Looze M, Roberts C, et al. Social Determinants of Health and Well-Being among Young People. Copenhagen: Health Behaviour in School-Aged Children (HBSC) Study: International Report from the 2009/2010 Survey; 2012.

34. Brown BB, Clasen DR, Eicher SA. Perceptions of peer pressure, pee conformity dispositions, and self-reported behavior among adolescents. Dev Psychol. 1986;22:521-30.

35. Bush K, Kivlahan DR, McDonell MB, Fihn SD, Bradley KA. The AUDIT alcohol consumption questions (AUDIT-C). An effective brief screening test for problem drinking. Arch Intern Med. 1998;158:1789-95.

36. Dawson DA, Smith SM, Saha TD, Rubinsky AD, Grant BF. Comparative performance of the AUDIT-C in screening for DSM-IV and DSM-5 alcohol use disorders. Drug Alcohol Depend. 2012;126:384-8.

37. Rumpf HJ, Wohlert T, Freyer-Adam J, Grothues J, Bischof G. Screening questionnaires for problem drinking in adolescents: Performance of AUDIT, AUDIT-C. CRAFFT and POSIT Eur Addict Res. 2013;19:121-7.

38. Adamson SJ, Sellman JD. A prototype screening instrument for cannabis use disorder: the Cannabis Use Disorders Identification Test (CUDIT) in an alcohol-dependent clinical sample. Drug Alcohol Rev. 2003;22:309-15.
39. Piontek D, Kraus L, Klempova D. Short scales to assess cannabis-related problems: a review of psychometric properties. Subst Abuse Treat Prev Policy. 2008;3:25.

40. Kessler RC, Adler LA, Barkley R, Biederman J, Conners CK, Faraone SV, et al. Patterns and predictors of attention-deficit/hyperactivity disorder persistence into adulthood: results from the national comorbidity survey replication. Biol Psychiatry. 2005;57:1442-51.

41. Stephenson MT, Velez LF, Chalela P, Ramirez A, Hoyle RH. The reliability and validity of the Brief Sensation Seeking Scale (BSSS-8) with young adult Latino workers: implications for tobacco and alcohol disparity research. Addiction. 2007;102:79-91.

42. Hoyle RH, Stephenson MT, Palmgreen P, Lorch EP, Donohew RL. Reliability and validity of a brief measure of sensation seeking. Pers Individ Dif. 2002;32:401-14.

43. Aluja A, Garcia O, Garcia LF. Psychometric properties of the ZuckermanKuhlman personality questionnaire (ZKPQ-III-R): a study of a shortened form. Pers Individ Dif. 2003;34:1083-97.

44. Aluja A, Rossier J, García LF, Angleitner A, Kuhlman M, Zuckerman M. A cross-cultural shortened form of the ZKPQ (ZKPQ-50-cc) adapted to English, French, German, and Spanish languages. Pers Individ Dif. 2006;41:619-28.

45. Sheehan DV, Lecrubier $Y$, Sheehan KH, Amorim P, Janavs J, Weiller E, et al. The Mini-International Neuropsychiatric Interview (M.I.N.I.): the development and validation of a structured diagnostic psychiatric interview for DSM-IV and ICD-10. J Clin Psychiatry. 1998;59 Suppl 20:22-33.

46. IBM Inc. IBM SPSS Statistics 20.0. 2011.

47. Flórez-Salamanca L, Secades-Villa R, Hasin DS, Cottler L, Wang S, Grant BF, et al. Probability and predictors of transition from abuse to dependence on alcohol, cannabis, and cocaine: results from the National Epidemiologic Survey on Alcohol and Related Conditions. Am J Drug Alcohol Abuse. 2013:39:168-79.

48. Ramo DE, Liu H, Prochaska JJ. Tobacco and marijuana use among adolescents and young adults: a systematic review of their co-use. Clin Psychol Rev. 2012;32:105-21.

\section{Submit your next manuscript to BioMed Central and take full advantage of:}

- Convenient online submission

- Thorough peer review

- No space constraints or color figure charges

- Immediate publication on acceptance

- Inclusion in PubMed, CAS, Scopus and Google Scholar

- Research which is freely available for redistribution 